\title{
The Relationship Between Response-Inhibitory Event-Related Potentials and Symptoms of Attention-Deficit/Hyperactivity Disorder in Adult Patients with Major Depressive Disorder
}

\author{
Eun Jee Kim¹, Young Joon Kwon ${ }^{1}$, Hwa-Young Lee ${ }^{1}$, Hee-Jung Yoon ${ }^{2}$, Ji Sun Kim ${ }^{凶}$, and Se-Hoon Shim ${ }^{1 凶}$ \\ ${ }^{1}$ Department of Psychiatry, College of Medicine, Soonchunhyang University Cheonan Hospital, Cheonan, Republic of Korea \\ ${ }^{2}$ The Korean Society of Infectious Diseases, Seoul, Republic of Korea
}

\begin{abstract}
Objective Attention-deficit and poor impulse control have frequently been observed in major depressive disorder (MDD) and attention-deficit and hyperactivity disorder (ADHD). Altered event-related potential (ERP) performance, such as GoNogo tasks, has been regarded as a neurocognitive process associated with attention and behavioral inhibition. The aim of this study was to investigate the association between Nogo ERP and adult ADHD in MDD.

Methods A total of 64 participants with MDD (32 comorbid with ADHD) and 32 healthy controls aged 19-45 years were recruited; they performed GoNogo paradigms during electroencephalogram measurement. Beck Depression Inventory (BDI), State-Trait Anxiety Inventory (STAI), and the Adult ADHD Self-Report Scale (ASRS) were evaluated. Clinical measures and GoNogo ERP were compared between three groups: depression with ADHD, depression without ADHD, and healthy controls.

Results MDD subjects with ADHD showed significantly decreased Nogo P3 amplitude at frontal electrode, compared with those without $\mathrm{ADHD}$ and healthy controls. MDD subjects with ADHD showed significantly longer Nogo N2 latency at frontal and frontocentral electrodes, compared with those without ADHD and healthy controls. In MDD subjects with ADHD, the Nogo P3 amplitude at the frontal electrode was negatively correlated with the ASRS score and inattention. The Nogo N2 latency at the frontal electrode was positively correlated with false alarm rate.

Conclusion The decreased Nogo P3 amplitude in the frontal area might be a potential biological marker for inattention in depressed patients with ADHD.

Psychiatry Investig 2020;17(10):996-1005
\end{abstract}

Key Words Event related potential, GoNogo, Adult, ADHD, Depression.

\section{INTRODUCTION}

In general, $5-10 \%$ of men and $10-25 \%$ of women are diagnosed with major depressive disorder (MDD) at least once in their lives. ${ }^{1}$ The main symptoms of MDD are depressed mood

\footnotetext{
Received: April 23, 2020 Revised: July 17, 2020

Accepted: August 24, 2020

$\triangle$ Correspondence: Ji Sun Kim, MD

Department of Psychiatry, College of Medicine, Soonchunhyang University Cheonan Hospital, 31 Suncheonhyang 6-gil, Dongnam-gu, Cheonan 31151, Republic of Korea

Tel: +82-41-570-2280, Fax: +82-41-592-3804, E-mail: ideal91@hanmail.net

$\square$ Correspondence: Se-Hoon Shim, MD, PhD

Department of Psychiatry, College of Medicine, Soonchunhyang University Cheonan Hospital, 31 Suncheonhyang 6-gil, Dongnam-gu, Cheonan 31151, Republic of Korea

Tel: +82-41-570-3853, Fax: +82-41-592-3804, E-mail: shshim2k@daum.net

(c) This is an Open Access article distributed under the terms of the Creative Commons Attribution Non-Commercial License (https://creativecommons.org/licenses/by$\mathrm{nc} / 4.0$ ) which permits unrestricted non-commercial use, distribution, and reproduction in any medium, provided the original work is properly cited.
}

based on subjective complaints or others' observation, loss of interest or pleasure, and decreased concentration. In addition to these mood symptoms, attention deficit, ${ }^{2,3}$ memory disturbance, ${ }^{4,5}$ decreased executive-control function, ${ }^{6,7}$ and poor response inhibition ${ }^{8}$ are observed in MDD. Attention deficit and poor response inhibition are also known to be the main clinical features of attention deficit and hyperactivity disorder (ADHD). ${ }^{9}$ Each disorder shows symptom overlap, including attention deficits, emotional sensitivity, and poor impulse control. ${ }^{10}$ Behavioral disturbances and response inhibition were commonly observed in patients with depressive disorder and ADHD, ${ }^{8,11}$

Moreover, both MDD and ADHD show high rates of coexistence with each other. The prevalence of ADHD in MDD was reported to vary between 5 and $16 \%{ }^{12,13}$ According to the National Comorbidity Survey Replication study, ${ }^{14} 18.6 \%$ of ADHD patients are diagnosed with MDD. In studies of adult diagnosed with $\mathrm{ADHD}, 35$ to $50 \%$ of adults diagnosed with 
ADHD had more than one depressive episode in their lifetime. ${ }^{15-17}$ In addition to higher levels of comorbidity, previous studies reported a genetic overlap between $\mathrm{ADHD}$ and MDD, while both disorders involve defective dopamine-reward circuit, and difficulty in emotional regulation. ${ }^{18}$

When MDD coexists with adult ADHD, more severe symptoms and poor prognosis are predicted, ${ }^{19,20}$ which incur more cost to society and individuals. ${ }^{21,22}$ Despite the importance of the detection of $\mathrm{ADHD}$, psychiatrists have not been used to diagnose and treat adult $\mathrm{ADHD}$, since ADHD was previously recognized as a childhood disease. In addition, ADHD is often overlooked in a clinical setting; psychiatrists are familiar with mood and anxiety symptoms, and they tend to diagnose mood or anxiety disorders in patients with ADHD symptoms. ${ }^{23}$ To provide proper treatment for MDD patients with comorbid ADHD, biological markers that can differentiate MDD and comorbid ADHD should be detected.

The GoNogo event-related potential (ERP) is known to be a biological indicator that reflects behavioral and response inhibition. ${ }^{24}$ Nogo N2 (N200) and P3 (P300) are well-known indicators of behavioral control. ${ }^{25}$ Specifically, the Nogo N2 component appears to reflect inhibitory control or conflict monitoring, ${ }^{26}$ while Nogo P3 indicates motor inhibition. ${ }^{27-29}$ The changes in Nogo N2 and P3 amplitudes have been investigated to compare the disease characteristics of inattention and poor impulse control in both MDD and ADHD; however, the results have been inconsistent. Many studies of MDD have reported increased Nogo N2 or decreased P3 amplitude in MDD patients compared to healthy control..$^{30-33}$ However, some studies showed no difference in Nogo N2 or P3 amplitude. ${ }^{30,31,33}$ ADHD patients were generally found to show decreased P3 amplitude. ${ }^{34-38}$ However, reports of change in the Nogo N2 amplitude in adult ADHD are inconsistent. ${ }^{34-36,39-42}$

Although it is clinically important to diagnose ADHD in MDD patients, and despite a possible neurobiological basis for overlapping symptoms, such as inattention and behavioral inhibition, there have been no reports of neurophysiological differences according to the presence or absence of ADHD in MDD patients. Because N2 and P3 are known to be associated with behavioral inhibition, we hypothesized that Nogo N2 and P3 differ in patients with MDD, depending on the presence of ADHD. Thus, our aim was to investigate the association between Nogo ERP and adult ADHD in MDD patients.

\section{METHODS}

\section{Subjects}

All cases were between the ages of 19 and 45 years. We included 64 participants ( 37 male and 27 female, mean age= $25.94 \pm 8.17$ years) diagnosed with MDD according to the cri- teria of the Diagnostic and Statistical Manual of Mental Disorder, fifth edition (DSM-5). Bipolar disorder and other mood disorders were excluded via clinical interviews. In addition, a mood disorder questionnaire was administered and those who answered 'yes' to at least 7 of the manic or hypomanic symptoms were excluded. ${ }^{43} \mathrm{MDD}$ subjects were classified into either the ADHD or the comparison group. All patients diagnosed with adult $\mathrm{ADHD}$ met the full criteria for ADHD according to the DSM-5 criteria based on Mini- International Neuropsychiatric Interview by clinicians. We classified 32 subjects into MDD with ADHD group (27 males and 5 females, mean age $=21.53 \pm 3.48$ years), and 32 were classified into the MDD without $\mathrm{ADHD}$ group (10 males and 22 females, mean age $=$ $30.34 \pm 9.14$ years). The healthy control group consisted of 32 physically and mentally healthy volunteers (13 males and 19 females, mean age $=27.87 \pm 5.95$ years) recruited from the local community through newspapers and posters. All patients with depression were drug-naive. None of the participants had mental retardation, a history of substance abuse/dependence, or head trauma. This study was approved by the Institutional Review Board and Ethics Committee of Soonchunhyang University Cheonan Hospital, and all experimental protocols were approved by the committee (2019-05-004).

\section{Clinical measures}

To evaluate social and emotional functioning, we applied the Beck Depression Inventory (BDI), the State-Trait Anxiety Inventory (STAI), and the Korean version of the Adult ADHD Self-Report Scale (ASRS v1.1). The BDI is a self-reporting examination developed to measure depression. BDI consists of 21 items, with each item score ranging from 0 to 3 , and the total score ranging from 0 to 63 . The higher scores are positively correlated with the severity of depression. ${ }^{44}$ The STAI is a selfreporting examination developed to measure two types of anxiety. The STAI consists of 40 items, with each item scored in the range of 1 to 4 . Higher scores are positively correlated with a higher level of anxiety. ${ }^{45}$ The Korean version of the Adult ADHD Self-Report Scale (ASRS v1.1) is a reliable and valid tool for screening and evaluating ADHD symptoms in adolescents and adults. The ASRS consists of 18 items (nine for inattention, and nine for hyperactivity/impulsivity). The answers that require careful evaluation are shaded in dark. Part A consists of six items. ADHD is predicted by four or more marks appearing in the dark-shaded boxes within Part A, warranting further examination. Part B consists of 12 items, and provides additional clues to the symptoms. ${ }^{46}$

\section{EEG data acquisition and analysis}

Subjects were seated approximately $60 \mathrm{~cm}$ away from the computer screen in a relaxed sitting position in a silent room. 
EEG was acquired using a NeuroScan SynAmps amplifier (Compumedicus USA, E1 Paso, TX, USA) with $64 \mathrm{Ag} / \mathrm{AgCl}$ electrodes mounted on a Quik Cap. Electrodes were placed as central $(\mathrm{Cz})$ and frontal $(\mathrm{Fz})$, and an earth electrode was placed fronto-parietal (FPz), according to the extended 10-20 placement scheme. An electrode was placed infra-orbitally to monitor eye movement. Reference electrodes were placed at the mastoid, and the impedance was less than $10 \mathrm{k} \Omega$. The bandpass filter was set at $(0.1-100) \mathrm{Hz}$, and sampled at $1,000 \mathrm{~Hz}$.

The EEG data were processed using CURRY 8. Gross artifacts were rejected by visual inspection by a trained person. Eye-movement artifacts were removed using the mathematical procedure in the preprocessing software. Data were filtered using a (0.1-30) Hz band-pass filter, and epoched from $100 \mathrm{~ms}$ pre-stimulus to $600 \mathrm{~ms}$ post-stimulus. These epochs were subtracted from the average value of the pre-stimulus interval for baseline correction. If any remaining epochs continued to have significant physiological artifacts (amplitude exceeding $\pm 75 \mu \mathrm{V}$ ) in any of the 62 electrode sites, they were excluded from further analysis. Only artifact-free epochs were averaged across trials and participants for ERP analysis. Based on the previous studies that Nogo ERP reflected behavioral inhibition, the present study included Nogo trials in ERP analysis.

\section{Behavioral task paradigm}

As stimuli for the GoNogo task, we applied the oddball paradigm' of auditory stimulation. ERPs were elicited binaurally through headphones. The subjects were instructed to press the spacebar as accurately and quickly as possible when the target tone appeared, and not to respond when the non-target tone appeared. There were 400 trials, which consisted of Go (85\% probability) and Nogo (15\% probability) conditions. The target tone (Nogo) was $1,500 \mathrm{~Hz}$, and the nontarget tone (Go) was $1,000 \mathrm{~Hz}$, with a 1,500 ms interval before the next trial. These stimuli were generated using E-prime software (Psychology Software Tools, Pittsburgh, PA, USA). In the Go condition, N200 (the most negative peak between 150 and $350 \mathrm{~ms}$ after stimulus onset) and the P300 (the most positive peak between 250 and $500 \mathrm{~ms}$ after stimulus onset) were investigated at the frontal (Fz), fronto-central (FCz), and central (Cz) electrodes. In the Nogo condition, the $\mathrm{N} 200$ and the P300 were investigated at the $\mathrm{Fz}, \mathrm{FCz}$, and $\mathrm{Cz}$ electrodes. We focused on the changes of $\mathrm{N} 2$ and $\mathrm{P} 3$ at the frontocentral electrode, because MDD and ADHD have been regarded as mental illnesses associated with frontal-lobe dysfunction, and previous studies of MDD or ADHD patients generally showed changes of $\mathrm{N} 2$ and $\mathrm{P} 3$ in the fronto-central regions. ${ }^{30,31,34,39,47}$ The time window we assumed was based on previous studies. ${ }^{48}$ To accumulate behavioral data, Go accuracy, Nogo accuracy, and reaction time were calculated based on the data of E-prime software.
The Nogo accuracy was calculated to determine the false-alarm rate of responses to non-target stimuli.

\section{Statistical analysis}

For descriptive statistics, we used frequency distributions, continuous variables, arithmetic means, and standard deviation. Groups were compared using the chi-square test for discontinuous variables. We used one-way analysis of variance (ANOVA) with a post hoc least significant difference (LSD) test to compare the scores of psychological and behavioral data between groups: the MDD with $\mathrm{ADHD}, \mathrm{MDD}$ without $\mathrm{ADHD}$, and healthy controls. N2, P3 amplitudes, and latencies of patients and healthy controls were initially evaluated by using repeated measures analysis of variance (ANOVA) with electrodes $(\mathrm{Fz}, \mathrm{FCz}$, and $\mathrm{Cz}$ ) as the within-subject factor, and groups (MDD with ADHD, MDD without ADHD, and healthy controls) as the between-subject factor. The multivariate analysis of variance (MANOVA), repeated measures ANOVA were used to adjust for each of the variables including age, sex, education and all of them together as covariates. We used MANOVA to compare the GoNogo ERPs between MDD with and without ADHD groups, and control for age, sex, education and depressive symptom as covariates. In addition, Spearman's correlation analysis was conducted between GoNogo ERP and psychological measures with a 5,000-bootstrap resampling technique to correct for multiple correlations. The bootstrap test is a weaker method than the Bonferroni test to solve the problem of multiple comparisons. However, the robustness and stability of the bootstrap test have been recognized by previous studies. ${ }^{49-51}$ Furthermore, the bootstrap test has been widely used in EEG analysis. ${ }^{48}$ We conducted a multiple regression analysis of Nogo P3 amplitude and psychological data that showed a significant association in the partial correlation analysis. Comparisons were considered significant at $\mathrm{p}<0.05$. All statistical analysis was done using SPSS version 21.0 (IBM Corp., Armonk, NY, USA).

\section{RESULTS}

\section{Subjects}

Table 1 presents the baseline demographic and clinical symptoms of MDD patients with and without ADHD, and those of healthy controls. The three groups differed significantly in age $(\mathrm{p}<0.001)$, sex $(\mathrm{p}<0.001)$, and education $(\mathrm{p}<0.001)$, based on by chi-square tests and analysis of variance (ANOVA) with a post hoc LSD test. The age of the patients diagnosed with ADHD was relatively low, because we targeted patients who received first-time examination at the hospital. The healthy control group showed significantly higher number of years of education than the MDD patient group $(\mathrm{p}<0.001)$. The MDD 
with ADHD group showed a significantly higher ASRS score than did the MDD without ADHD group ( $<<0.001)$. There were no significant differences in STAI state, STAT trait, or $\mathrm{BDI}$ between the MDD with $\mathrm{ADHD}$ group, and the MDD without ADHD group.

\section{Behavioral outcomes}

Table 2 presents the Nogo N2 and P3 behavioral outcomes. The MDD patients performed significantly worse in the GoNogo task on Go accuracy (MDD with ADHD, 93.31 \pm 8.81 ; MDD without $\mathrm{ADHD}, 95.40 \pm 7.07$; healthy control, 99.75 \pm 0.62$)$ and Nogo accuracy (MDD with ADHD, 85.37 \pm 14.07 ; MDD with-

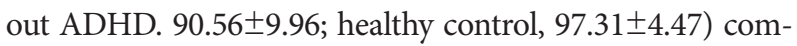
pared with the healthy controls, who had significantly shorter reaction time than did the MDD patient group (MDD with ADHD, 476.02 \pm 102.76 ; MDD without ADHD, 458.80 \pm 86.27 , healthy control, 414.92 \pm 68.27$)$. There was no significant difference in reaction time between the MDD with ADHD and MDD without ADHD groups. The three groups of subjects showed significant differences in the false-alarm rate (MDD with $\mathrm{ADHD}, 14.62 \pm 14.07$; MDD without $\mathrm{ADHD}, 9.43 \pm 9.96$; healthy controls, $2.68 \pm 4.47)$. The healthy controls showed a significantly lower false-alarm rate than those with MDD with $\operatorname{ADHD}(\mathrm{p}<0.001)$ and MDD without ADHD $(\mathrm{p}=0.010)$.

\section{ERP}

\section{Amplitude}

Table 3 presents the means and standard deviations for Nogo N2 and P3 amplitudes. Figure 1 shows the grand average of the Nogo ERPs at the Fz electrode for each group. The three groups showed significant differences in Nogo P3 amplitude

Table 1. Comparison of baseline demographic data and initial clinical symptoms of MDD patients with and without ADHD and healthy controls

\begin{tabular}{|c|c|c|c|c|c|c|c|}
\hline & \multirow{2}{*}{$\begin{array}{c}\text { With ADHD } \\
\quad(\mathrm{N}=32)\end{array}$} & \multirow{2}{*}{$\begin{array}{c}\begin{array}{c}\text { Without ADHD } \\
(\mathrm{N}=32)\end{array} \\
\text { Mean } \pm \text { SD or } \mathrm{N}(\%)\end{array}$} & \multirow{2}{*}{$\begin{array}{l}\text { Healthy control } \\
\qquad(\mathrm{N}=32)\end{array}$} & \multirow[b]{2}{*}{$\mathrm{p}$} & \multicolumn{3}{|c|}{ Pairwise test, $\mathrm{p}$ value } \\
\hline & & & & & $\begin{array}{c}\text { With ADHD } \\
\text { vs. without } \\
\text { ADHD }\end{array}$ & $\begin{array}{c}\text { With ADHD } \\
\text { vs. control }\end{array}$ & $\begin{array}{c}\text { Without ADHD } \\
\text { vs. control }\end{array}$ \\
\hline Age (years) & $21.53 \pm 3.48$ & $30.34 \pm 9.14$ & $27.87 \pm 5.95$ & $<0.001$ & $<0.001$ & $<0.001$ & 0.139 \\
\hline Sex & & & & $<0.001$ & $<0.001$ & $<0.001$ & 0.434 \\
\hline Male & $27(84.4)$ & $10(31.2)$ & $13(40.6)$ & & & & \\
\hline Female & $5(15.6)$ & $22(68.8)$ & $19(59.4)$ & & & & \\
\hline Education (years) & $12.09 \pm 1.80$ & $13.37 \pm 1.69$ & $14.87 \pm 2.37$ & $<0.001$ & 0.011 & $<0.001$ & 0.003 \\
\hline ASRS & $41.59 \pm 12.57$ & $28.62 \pm 12.56$ & $6.25 \pm 4.39$ & $<0.001$ & $<0.001$ & $<0.001$ & $<0.001$ \\
\hline Inattention & $23.03 \pm 5.37$ & $15.50 \pm 7.50$ & $4.53 \pm 3.33$ & $<0.001$ & $<0.001$ & $<0.001$ & $<0.001$ \\
\hline Hyperactivity & $17.68 \pm 6.03$ & $13.12 \pm 6.31$ & $1.71 \pm 1.81$ & $<0.001$ & 0.001 & $<0.001$ & $<0.001$ \\
\hline STAI state & $67.03 \pm 6.78$ & $63.03 \pm 10.88$ & $31.84 \pm 7.29$ & $<0.001$ & 0.064 & $<0.001$ & $<0.001$ \\
\hline STAI trait & $66.40 \pm 6.70$ & $64.21 \pm 10.64$ & $34.21 \pm 8.38$ & $<0.001$ & 0.319 & $<0.001$ & $<0.001$ \\
\hline BDI & $32.96 \pm 9.69$ & $32.59 \pm 11.40$ & $2.53 \pm 2.98$ & $<0.001$ & 0.865 & $<0.001$ & $<0.001$ \\
\hline
\end{tabular}

One-way analysis of variance (ANOVA) along with a post hoc least significant difference test for comparison of the three groups. MDD: major depressive disorder, ADHD: attention deficit and hyperactivity disorder, ASRS: The Korean version of the Adult ADHD Self-Report Scale, STAI: State-Trait Anxiety Inventory, BDI: Beck Depression Inventory, SD: standard deviation

Table 2. Comparison of behavioral outcomes among MDD patients with and without ADHD and healthy controls

\begin{tabular}{|c|c|c|c|c|c|c|c|c|}
\hline & \multirow{2}{*}{$\begin{array}{l}\text { With ADHD } \\
\qquad(\mathrm{N}=32)\end{array}$} & \multirow{2}{*}{ 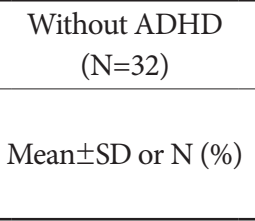 } & \multirow{2}{*}{$\begin{array}{l}\text { Healthy control } \\
\qquad(\mathrm{N}=32)\end{array}$} & \multirow[b]{2}{*}{$\mathrm{F}$} & \multirow[b]{2}{*}{$\mathrm{p}$} & \multicolumn{3}{|c|}{ Pairwise test, $\mathrm{p}$ value } \\
\hline & & & & & & $\begin{array}{c}\text { With ADHD } \\
\text { vs. without } \\
\text { ADHD }\end{array}$ & $\begin{array}{l}\text { With ADHD } \\
\text { vs. control }\end{array}$ & $\begin{array}{c}\text { Without } \\
\text { ADHD vs. } \\
\text { control }\end{array}$ \\
\hline Go accuracy (\%) & $93.31 \pm 8.81$ & $95.40 \pm 7.07$ & $99.75 \pm 0.62$ & 8.069 & $<0.001$ & 0.203 & $<0.001$ & 0.009 \\
\hline Nogo accuracy (\%) & $85.37 \pm 14.07$ & $90.56 \pm 9.96$ & $97.31 \pm 4.47$ & 10.834 & $<0.001$ & 0.047 & $<0.001$ & 0.010 \\
\hline False alarm rate (\%) & $14.62 \pm 14.07$ & $9.43 \pm 9.96$ & $2.68 \pm 4.47$ & 10.834 & $<0.001$ & 0.047 & $<0.001$ & 0.010 \\
\hline Reaction time (ms) & $476.02 \pm 102.76$ & $458.80 \pm 86.27$ & $414.92 \pm 68.79$ & 4.191 & 0.018 & 0.431 & 0.006 & 0.047 \\
\hline
\end{tabular}

One-way analysis of variance (ANOVA) combined with a post hoc least significant difference test for comparison of the three groups. MDD: major depressive disorder, ADHD: attention deficit and hyperactivity disorder, SD: standard deviation 
Table 3. Comparison of the amplitude and latencies among MDD patients with and without ADHD and healthy controls

\begin{tabular}{|c|c|c|c|c|c|c|c|c|}
\hline & \multirow{2}{*}{$\begin{array}{c}\text { With ADHD } \\
\quad(\mathrm{N}=32)\end{array}$} & \multirow{2}{*}{$\begin{array}{c}\begin{array}{c}\text { Without ADHD } \\
(\mathrm{N}=32)\end{array} \\
\text { Mean } \pm \text { SD or } \mathrm{N}(\%)\end{array}$} & \multirow{2}{*}{$\begin{array}{l}\text { Healthy control } \\
\qquad(\mathrm{N}=32)\end{array}$} & \multirow[b]{2}{*}{$\mathrm{F}$} & \multirow[b]{2}{*}{$\mathrm{p}$} & \multicolumn{3}{|c|}{ Pairwise test, $\mathrm{p}$ value } \\
\hline & & & & & & $\begin{array}{c}\text { With ADHD } \\
\text { vs. without } \\
\text { ADHD }\end{array}$ & $\begin{array}{c}\text { With ADHD } \\
\text { vs. control }\end{array}$ & $\begin{array}{c}\text { Without } \\
\text { ADHDvs. } \\
\text { control }\end{array}$ \\
\hline \multicolumn{9}{|l|}{ Amplitude (uV) } \\
\hline $\mathrm{N} 2$ frontal & $-5.99 \pm 3.41$ & $-3.63 \pm 3.48$ & $-6.15 \pm 3.14$ & 2.567 & 0.082 & 0.140 & 0.663 & 0.031 \\
\hline N2 fronto-central & $-4.93 \pm 3.19$ & $-3.14 \pm 4.20$ & $-5.80 \pm 2.66$ & 3.055 & 0.052 & 0.520 & 0.140 & 0.017 \\
\hline $\mathrm{N} 2$ central & $-2.96 \pm 2.39$ & $-2.51 \pm 2.74$ & $-3.52 \pm 2.61$ & 0.466 & 0.629 & 0.851 & 0.390 & 0.449 \\
\hline P3 frontal & $0.84 \pm 3.87$ & $2.63 \pm 4.14$ & $4.22 \pm 3.27$ & 6.005 & 0.004 & 0.036 & 0.001 & 0.142 \\
\hline P3 fronto-central & $4.38 \pm 4.52$ & $5.23 \pm 5.23$ & $6.92 \pm 3.79$ & 2.508 & 0.087 & 0.233 & 0.028 & 0.254 \\
\hline P3 central & $5.90 \pm 4.13$ & $5.52 \pm 4.19$ & $7.56 \pm 3.69$ & 1.561 & 0.216 & 0.834 & 0.212 & 0.100 \\
\hline \multicolumn{9}{|l|}{ Latency (ms) } \\
\hline N2 frontal & $263.12 \pm 37.84$ & $251.40 \pm 40.47$ & $244.87 \pm 27.06$ & 3.158 & 0.047 & 0.039 & 0.019 & 0.768 \\
\hline $\mathrm{N} 2$ fronto-central & $257.09 \pm 24.62$ & $245.59 \pm 39.29$ & $246.15 \pm 16.42$ & 4.378 & 0.015 & 0.004 & 0.050 & 0.264 \\
\hline N2 central & $254.37 \pm 22.23$ & $245.25 \pm 32.54$ & $246.34 \pm 15.09$ & 2.532 & 0.085 & 0.027 & 0.147 & 0.363 \\
\hline P3 frontal & $379.34 \pm 32.44$ & $366.96 \pm 41.54$ & $364.37 \pm 18.38$ & 2.891 & 0.061 & 0.019 & 0.091 & 0.430 \\
\hline P3 fronto-central & $370.46 \pm 36.66$ & $358.96 \pm 36.94$ & $363.34 \pm 18.30$ & 2.649 & 0.076 & 0.040 & 0.607 & 0.075 \\
\hline P3 central & $369.53 \pm 44.25$ & $359.15 \pm 36.17$ & $362.78 \pm 23.11$ & 1.880 & 0.159 & 0.064 & 0.452 & 0.201 \\
\hline
\end{tabular}

The multivariate analysis of variance (MANOVA), repeated measures ANOVA was used to control for age, sex, and education as covariates. MDD: major depressive disorder, ADHD: attention deficit and hyperactivity disorder, SD: standard deviation

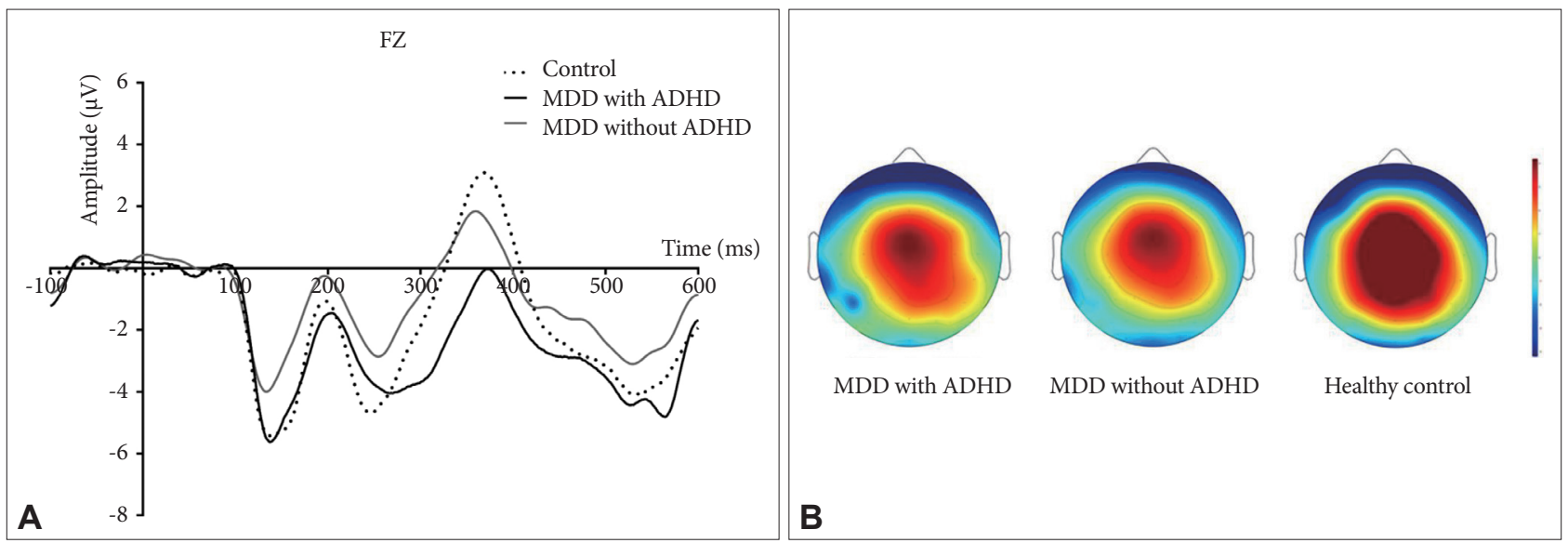

Figure 1. A: The grand average Nogo N2 and P3 waveforms at Fz in MDD patients with and without ADHD and healthy controls. B: Topoplot showing average activation across the scalp between (300 and 550) ms for MDD patients with for review only and without ADHD and healthy controls. MDD: major depressive disorder; ADHD: attention deficit and hyperactivity disorder, Fz: frontal electrode.

at the frontal electrode (pre-adjusted, $\mathrm{p}=0.003$; age-adjusted, $\mathrm{p}=0.007$; sex-adjusted, $\mathrm{p}=0.001$; education-adjusted, $\mathrm{p}=0.011$; age, sex and education-adjusted, $\mathrm{p}=0.004)$. Also, compared with the healthy controls, the MDD with $\mathrm{ADHD}$ group showed a significantly lower Nogo P3 amplitude at the frontal electrode (pre-adjusted, $\mathrm{p}=0.001$; age-adjusted, $\mathrm{p}=0.002$; sex-adjusted, $\mathrm{p}<0.001$; education-adjusted, $\mathrm{p}=0.003$; age, sex and education-adjusted, $\mathrm{p}=0.001)$. However, the difference in Nogo P3 amplitude between group manifesting MDD with and without ADHD was significant only in sex-adjusted and total (in- cluding age, sex and education) adjusted values (sex-adjusted, $\mathrm{p}=0.013$; age, sex and education-adjusted, $\mathrm{p}=0.036$ ). When depressive symptoms were controlled by covariates within MDD patient groups, except for healthy controls, the difference in the Nogo P3 amplitude at the frontal electrode was not significant $(\mathrm{p}=0.067)$.

\section{Latency}

Table 3 displays the means and standard deviations for amplitude and latency of Nogo N2 and P3. Figure 1 shows the 
grand average of the Nogo ERPs at the Fz electrode for each group. The three groups showed significant differences in sexadjusted and total (including age, sex and education) adjusted Nogo N2 latency at the frontal (age-adjusted, $\mathrm{p}=0.026$; age, sex and education-adjusted, $\mathrm{p}=0.047$ ) and frontocentral electrode (age-adjusted, $\mathrm{p}=0.032$; age, sex and education-adjusted, $\mathrm{p}=$ 0.015). The MDD with ADHD group showed a significantly longer Nogo N2 latency at the frontal (age-adjusted, $\mathrm{p}=0.036$; age, sex and education-adjusted, $\mathrm{p}=0.039$ ) and frontocentral electrodes (age-adjusted, $\mathrm{p}=0.015$; age, sex and education-adjusted, $\mathrm{p}=0.004$ ) than did the MDD without ADHD group. The MDD with ADHD group showed significantly longer Nogo N2 latency at the frontal (age-adjusted, $\mathrm{p}=0.009$; age, sex and education-adjusted, $\mathrm{p}=0.019$ ) and frontocentral electrodes (age-adjusted, $\mathrm{p}=0.026$; age, sex and education-adjusted, $\mathrm{p}=$ $0.050)$ than did the healthy controls. No significant differences in latency were found between the MDD without ADHD group and the healthy controls. When depressive symptoms were controlled by covariates within MDD patient groups, except for healthy controls, the difference in the Nogo N2 latency at the frontal $(\mathrm{p}=0.033)$ and frontocentral $(\mathrm{p}=0.009)$ electrodes was significant.

\section{Correlations}

In correlation analysis between the clinical symptom and ERPs measure in MDD with ADHD groups, the Nogo P3 amplitude at the frontal electrode was negatively correlated with the ASRS score $(\mathrm{r}=-0.358, \mathrm{p}=0.044)$ (Figure 2A), and inattention $(\mathrm{r}=-0.438, \mathrm{p}=0.012)$ (Figure $2 \mathrm{~B})$. Multiple regression anal- yses showed a significant association between Nogo P3 amplitude and inattention after adjusting age, sex and education. $(\mathrm{B}=-0.130, \mathrm{p}=0.045)$. Nogo $\mathrm{N} 2$ latency at the frontal electrode was positively correlated with the false-alarm rate $(\mathrm{r}=0.371$, $\mathrm{p}=0.037)$.

\section{DISCUSSION}

Our study aimed to identify the differences of Nogo N2 and P3 ERP between the MDD with and without ADHD groups. As we hypothesized, the Nogo P3 amplitude varied according to the presence or absence of ADHD. The MDD with ADHD group showed significantly more decreased Nogo P3 amplitude at the frontal electrode compared with those without ADHD and the healthy controls. Additionally, the Nogo N2 latency also differed according to the presence or absence of ADHD. The MDD with ADHD group had a significantly longer Nogo N2 latency at the frontal and frontocentral electrode compared with those without ADHD and healthy controls.

First, the present study showed that Nogo P3 amplitude in the frontal electrode was significantly attenuated in the MDD with ADHD group relative to the MDD without ADHD and healthy controls. This finding was observed whether or not it was adjusted for age, sex and education as covariates. Although there has been no previous study that evaluated Nogo N2 and P3 in patients with MDD comorbid with ADHD, our results are comparable to the previous studies showing decreased Nogo P3 amplitude in MDD subjects compared to normal patients. $^{30-32}$ The previous study showed a significant negative
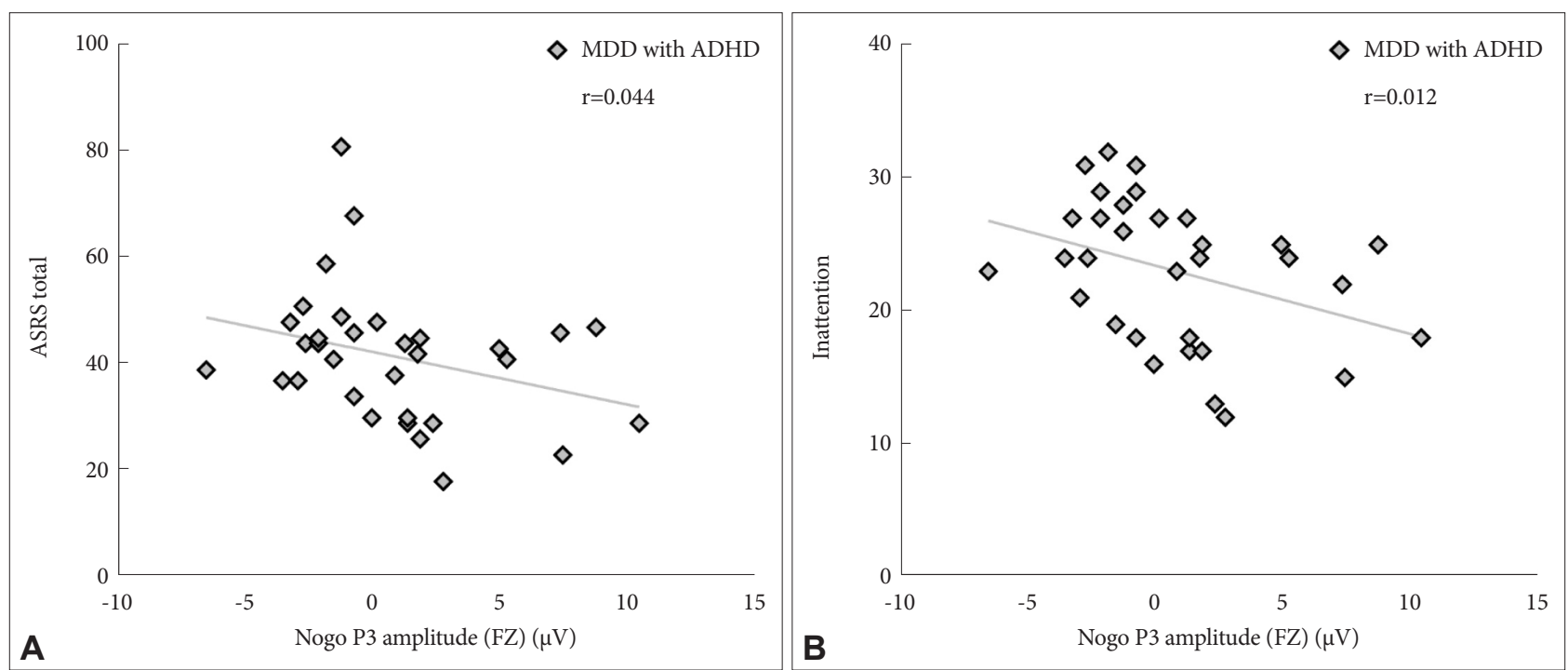

Figure 2. The Nogo P3 amplitude at Fz showed significant correlation with Adult ADHD self-report scales (ASRS) and the inattention subscale of ASRS. A: Scatter plots of Nogo P3 amplitude at Fz and total ASRS score change in MDD with ADHD patients. Spearman's correlation analysis was conducted between GoNogo ERP and psychological measures. B: Scatter plots of Nogo P3 amplitude at Fz and inattention score change in MDD with ADHD patients. Spearman's correlation analysis was conducted between GoNogo ERP and psychological measures. Fz: frontal electrode, MDD: major depressive disorder, ADHD: attention deficit and hyperactivity disorder, ASRS: The Korean version of the Adult ADHD Self-Report Scale. 
correlation between depressive symptoms and Nogo P3 amplitudes. ${ }^{32}$ Moreover, patients with ADHD also showed decreased P3 amplitudes, compared with healthy controls. ${ }^{34-38}$ In particular, the inattention subscale in ASRS and P3 amplitude showed a significant negative correlation. ${ }^{37}$ The present study also showed that Nogo P3 amplitudes were negatively correlated with inattention and ASRS score. Regarding P3 reflecting attention, working memory, and problem solving, ${ }^{26}$ our results indicate that the difference of Nogo P3 amplitudes between the MDD with and without ADHD might reflect the difference of attentional control between the two groups. In addition, the present study showed that MDD with ADHD had decreased Nogo P3 amplitude, compared with that of healthy controls. In contrast, no difference was found between the $\mathrm{MDD}$ without $\mathrm{ADHD}$ and healthy controls existed. Moreover, there was no significant correlation between Nogo P3 amplitude and depression symptoms, suggesting that Nogo P3 amplitude was related to inattention, rather than depression. It is possible that the results of previous MDD patient studies that showed significantly decreased Nogo P3 amplitudes might cause the characteristic of population including patients who had ADHD symptoms.

False-alarm rates and commission errors reflect poor motor-response inhibition, whereas reaction time and omission error reflect poor sustained and selective attention. ${ }^{52,53}$ In behavioral tasks, MDD with ADHD patients showed increased omission rates and reaction times, compared to healthy controls in this study. The results are comparable to previous studies that found ADHD patients had a longer reaction time ${ }^{38}$ and omission rate, ${ }^{52,54}$ compared to the healthy population. Additionally, regarding omission error reflecting poor sustained and selective attention, ${ }^{53}$ this result also suggests that ADHD patients showed poor attentional control. However, there was no significant difference in omission rate (Go accuracy) and reaction time based on comorbid ADHD in this study. These results suggest that omission error and reaction time do not reflect ADHD per se, but rather the attention deficit that appears in both MDD and ADHD.

Instead, the present study showed a significant difference in false-alarm rate and commission rate (Nogo accuracy) in MDD patients depending on the presence or absence of ADHD. Previous studies reported that $A D H D$ patients had a higher falsealarm rate than did the healthy controls. ${ }^{36,38}$ Our results suggest a possible difference in impulse control between MDD with and without ADHD patients.

Our results show that the Nogo P3 amplitude was correlated with the inattention scale of ASRS, but not with the falsealarm rate and commission rate, suggesting that the Nogo P3 amplitude reflects inattention, rather than poor impulse control. Nogo P3 amplitude might be a candidate marker reflecting the inattention characteristic of ADHD. Although the difference of Nogo P3 amplitude in the MDD group was not significant when depressive symptom was controlled, the multiple regression analysis showed a significant correlation between Nogo P3 amplitude and inattention. Further study is needed to corroborate the finding even after controlling clinical symptoms. The absence of differences in reaction time and omission rate between MDD with and without ADHD in the study might be attributed to the relatively easy GoNogo tasks, or the discrepancies between behavioral tasks and neurophysiological tasks. Also, due to the relatively small sample size, no possible correlation may exist between the clinical scale and the ERPs. Further study is needed to identify neurophysiological biomarkers associated with behavioral inhibition in the larger homogenous $\mathrm{ADHD}$ population with progressed behavioral tasks.

The present study showed that N2 latency in the frontal and frontocentral electrodes was longer in the MDD with ADHD group, than in the MDD without ADHD group. No previous Nogo N2 study of MDD with ADHD subjects has been reported. No study has reported significant changes in N2 latency in patient with MDD alone. ${ }^{30,31}$ Moreover, few studies have reported changes in $\mathrm{N} 2$ latency among $\mathrm{ADHD}$ patients using the GoNogo paradigm, and no consistent findings have been reported. ${ }^{36,42}$ Among the Nogo ERP studies involving patients with ADHD, Fallgatter et al. ${ }^{36}$ reported that patients with ADHD showed longer $\mathrm{N} 2$ latency and longer reaction time compared with healthy controls. The previous studies using different paradigms have also reported a longer N2 latency in patients with ADHD than in healthy controls, which might reflect a lack of retrieval ability in the patients with $\mathrm{ADHD} .{ }^{55,56} \mathrm{In}$ a study with childhood ADHD patients using the oddball paradigm, N2 latencies were longer in the frontocentral electrodes, and reaction times were longer than in healthy controls. ${ }^{56}$ Additionally, in a study with adult ADHD patients using N-back task, the N2 latencies were longer in the occipital electrode, without any significant difference in reaction time. ${ }^{55}$

Despite the lack of consistent findings related to N2 latency in patients with $\mathrm{ADHD},{ }^{47,57}$ in the study of Sunohara et al., ${ }^{57}$ patients with ADHD showed shorter N2 latency, shorter reaction time, and higher false-alarm rate. These results suggest that patients with ADHD classified information more rapidly and in less detail compared with the controls.

The previous studies reported that the $\mathrm{N} 2$ component was associated with an unexpected degree of stimulation, along with response identification and selection. ${ }^{58,59}$ Comparable to previous studies, a longer $\mathrm{N} 2$ latency in depressed patients with ADHD in this study suggests an additional cognitive process involved in classifying the stimulation. ${ }^{56}$ Unexpectedly, there was no significant difference in reaction time between the $\mathrm{MDD}$ with $\mathrm{ADHD}$ and without $\mathrm{ADHD}$ groups. Furthermore, 
the Nogo N2 latencies were not correlated with reaction time, but with false-alarm rate. Considering the previous study that showed N2 in the GoNogo task was mainly associated with conflict monitoring processes, ${ }^{60}$ a longer N2 latency in depressed patients with ADHD might reflect more difficult conflict monitoring and additional cognitive load in processing the tasks. This would leads to weaker conflict monitoring, and causes more false alarm errors in the MDD patients with ADHD. Further study is needed to validate the inconsistent results reported previously due to differences in study populations and tasks.

This study has several limitations. First, the patient groups and healthy controls were not matched for age, sex, and education, despite adjustment for demographic variables as covariates. However, previous studies reported a generally higher rate of ADHD in males than in females from childhood into adulthood. ${ }^{61}$ Patients with ADHD might be identified in early adulthood because of the nature of childhood onset and developmental pathophysiology, compared with those manifesting other psychiatric disorders. Although the discrepancy in age and sex between the study groups in this study might reflect clinical reality, a further study using a matched population is needed. Second, the findings are hard to generalize due to the relatively small sample size. Third, the subtypes of ADHD were not considered, and only DSM-5-based physician diagnosis and self-reported ASRS tests were used; which suggests the need for further studies using clinical diagnostic tools to corroborate our results. In addition, psychological scales measuring impulsivity, such as the Barrette impulsivity scale, were not evaluated in the study. Further study should consider direct psychological measurement of impulsivity. Finally, the present study did not investigate source activity of changed ERP of sensor level. Therefore, another study is needed for source analysis to confirm the role of prefrontal activity for attention and behavioral control in MDD with ADHD.

Despite these limitations, to the best of our knowledge, this study is the first of its kind to examine neurophysiological differences among patients with MDD according to the presence or absence of ADHD. Our study suggests that decreased Nogo P3 amplitude in the frontal area might be a candidate for a biological marker for inattention in ADHD co-morbid with MDD.

\section{Acknowledgments}

This work was supported by the Basic Science Research Program through the National Research Foundation of Korea (NRF), funded by the Ministry of Education (2017R1D1A3B03030974). This study was also supported by Soonchunhyang University.

\section{Conflicts of Interest}

The authors have no potential conflicts of interest to disclose.

\section{Author Contributions}

Conceptualization: all authors. Data curation: Eun Jee Kim, Ji Sun Kim,
Se-Hoon Shim. Formal analysis: Eun Jee Kim, Ji Sun Kim, Se-Hoon Shim. Funding acquisition: Ji Sun Kim, Se-Hoon Shim. Investigation: all authors. Methodology: all authors. Project administration: Ji Sun Kim, Se-Hoon Shim. Resources: Eun Jee Kim, Ji Sun Kim, Se-Hoon Shim. Softwear: Eun Jee Kim, Ji Sun Kim, Se-Hoon Shim. Supervision: Ji Sun Kim, Se-Hoon Shim. Validation: Ji Sun Kim, Se-Hoon Shim. Visualization: Eun Jee Kim, Ji Sun Kim, Se-Hoon Shim. Writing_original draft: all authors. Writingreview\&editing : Eun Jee Kim, Ji Sun Kim, Se-Hoon Shim.

\section{ORCID iDs}

Eun Jee Kim

Young Joon Kwon

Hwa-Young Lee

Hee-Jung Yoon

Ji Sun Kim

Se-Hoon Shim

https://orcid.org/0000-0003-3234-9314

https://orcid.org/0000-0001-9340-0895

https://orcid.org/0000-0002-2749-6232

https://orcid.org/0000-0001-9860-4774

https://orcid.org/0000-0003-2472-4591

https://orcid.org/0000-0002-3137-6591

\section{REFERENCES}

1. Min KJ, Lee MS, Jeong JH. Textbook of Neuropsychiatry (3rd Ed). In: Korean Neuropsychiatric Association, Editor. Depressive Disorder. Seoul: iMiS Company Press, 2017, p.279-297.

2. Purcell R, Maruff P, Kyrios M, Pantelis C. Neuropsychological function in young patients with unipolar major depression. Psychol Med 1997;27:1277-1285.

3. Paelecke-Habermann Y, Pohl J, Leplow B. Attention and executive functions in remitted major depression patients. J Affect Disord 2005;89: 125-135.

4. Austin MP, Mitchell P, Wilhelm K, Parker G, Hickie I, Brodaty H, et al. Cognitive function in depression: a distinct pattern of frontal impairment in melancholia? Psychol Med 1999;29:73-85.

5. Sweeney JA, Kmiec JA, Kupfer DJ. Neuropsychologic impairments in bipolar and unipolar mood disorders on the CANTAB neurocognitive battery. Biol Psychiatry 2000;48:674-684.

6. Ruchsow M, Herrnberger B, Beschoner P, Grön G, Spitzer M, Kiefer $M$. Error processing in major depressive disorder: evidence from eventrelated potentials. J Psychiatr Res 2006;40:37-46.

7. Chiu PH, Deldin PJ. Neural evidence for enhanced error detection in major depressive disorder. Am J Psychiatry 2007;164:608-616.

8. Barkley RA. The executive functions and self-regulation: an evolutionary neuropsychological perspective. Neuropsychol Rev 2001;11:1-29.

9. Volkow ND, Swanson JM. Adult attention deficit-hyperactivity disorder. N Engl J Med 2013;369:1935-1944.

10. Kim JS, Kim DW, Kwon YJ, Lee HY, Kim S, Shim SH. The relationship between auditory evoked potentials and symptoms of attention-deficit/hyperactivity disorder in adult patients with major depressive disorder. Int J Psychophysiol 2019;142:50-56.

11. Barkley RA. Behavioral inhibition, sustained attention, and executive functions: constructing a unifying theory of ADHD. Psychol Bull 1997; 121:65.

12. Di Nicola M, Sala L, Romo L, Catalano V, Even C, Dubertret C, et al. Adult attention-deficit/hyperactivity disorder in major depressed and bipolar subjects: role of personality traits and clinical implications. Eur Arch Psychiatry Clin Neurosci 2014;264:391-400.

13. Bond DJ, Hadjipavlou G, Lam RW, McIntyre RS, Beaulieu S, Schaffer A, et al. The Canadian Network for Mood and Anxiety Treatments (CANMAT) task force recommendations for the management of patients with mood disorders and comorbid attention-deficit/hyperactivity disorder. Ann Clin Psychiatry 2012;24:23-37.

14. Kessler RC, Adler L, Barkley R, Biederman J, Conners CK, Demler O, et al. The prevalence and correlates of adult ADHD in the United States: results from the National Comorbidity Survey Replication. Am J Psychiatry 2006;163:716-723.

15. Biederman J, Faraone SV, Spencer T, Wilens T, Norman D, Lapey KA, et al. Patterns of psychiatric comorbidity, cognition, and psychosocial 
functioning in adults with attention deficit hyperactivity disorder. Am J Psychiatry 1993;150:1792-1798.

16. Kooij J, Burger H, Boonstra A, Van der Linden P, Kalma L, Buitelaar J. Efficacy and safety of methylphenidate in 45 adults with attention-deficit/hyperactivity disorder. A randomized placebo-controlled doubleblind cross-over trial. Psychol Med 2004;34:973-982.

17. Spencer T, Biederman J, Wilens T, Doyle R, Surman C, Prince J, et al. A large, double-blind, randomized clinical trial of methylphenidate in the treatment of adults with attention-deficit/hyperactivity disorder. Biol Psychiatry 2005;57:456-463.

18. Yüce M, Uçar F, Say GN. ADHD - New Directions in Diagnosis and Treatment. In: Norvilitis JM, Editor. Comorbid Conditions in Child and Adolescent Patients Diagnosed with Attention Deficit/Hyperactivity Disorder. IntechOpen Press, 2015, p.85-98.

19. Sobanski E, Brüggemann D, Alm B, Kern S, Deschner M, Schubert T, et al. Psychiatric comorbidity and functional impairment in a clinically referred sample of adults with attention-deficit/hyperactivity disorder (ADHD). Dev Med Child Neurol 2007;257:371-377.

20. Biederman J, Ball SW, Monuteaux MC, Mick E, Spencer TJ, McCREARY M, et al. New insights into the comorbidity between ADHD and major depression in adolescent and young adult females. J Am Acad Child Adolese Psychiatry 2008;47:426-434.

21. Fischer AG, Bau CH, Grevet EH, Salgado CA, Victor MM, Kalil KL, et al. The role of comorbid major depressive disorder in the clinical presentation of adult ADHD. J Psychiatr Res 2007;41:991-996.

22. Secnik K, Swensen A, Lage MJ. Comorbidities and costs of adult patients diagnosed with attention-deficit hyperactivity disorder. Pharmacoeconomics 2005;23:93-102.

23. McIntosh D, Kutcher S, Binder C, Levitt A, Fallu A, Rosenbluth M. Adult ADHD and comorbid depression: a consensus-derived diagnostic algorithm for ADHD. Neuropsychiatr Dis Treat 2009;5:137-150.

24. Bokura H, Yamaguchi S, Kobayashi S. Electrophysiological correlates for response inhibition in a Go/NoGo task. Clin Neurophysiol 2001; 112:2224-2232.

25. Patel SH, Azzam PN. Characterization of N200 and P300: selected studies of the event-related potential. Int J Med Sci 2005;2:147-154.

26. Downes M, Bathelt J, De Haan M. Event-related potential measures of executive functioning from preschool to adolescence. Dev Med Child Neurol 2017;59:581-590.

27. Enriquez-Geppert S, Konrad C, Pantev C, Huster RJ. Conflict and inhibition differentially affect the N200/P300 complex in a combined go/ nogo and stop-signal task. Neuroimage 2010;51:877-887.

28. Dimoska A, Johnstone SJ, Barry RJ. The auditory-evoked N2 and P3 components in the stop-signal task: indices of inhibition, responseconflict or error-detection? Brain Cogn 2006;62:98-112.

29. Bruin K, Wijers A, Van Staveren A. Response priming in a go/nogo task: do we have to explain the go/nogo N2 effect in terms of response activation instead of inhibition? Clin Neurophysiol 2001;112:1660-1671.

30. Zhang BW, Xu J, Chang Y. The effect of aging in inhibitory control of major depressive disorder revealed by event-related potentials. Front Hum Neurosci 2016;10:116.

31. Ruchsow M, Groen G, Kiefer M, Beschoner P, Hermle L, Ebert D, et al. Electrophysiological evidence for reduced inhibitory control in depressed patients in partial remission: a Go/Nogo study. Int J Psychophysiol 2008;68:209-218.

32. Zhang BW, Zhao L, Xu J. Electrophysiological activity underlying inhibitory control processes in late-life depression: a Go/Nogo study. Neurosci Lett 2007;419:225-230.

33. Kaiser S, Unger J, Kiefer M, Markela J, Mundt C, Weisbrod M. Executive control deficit in depression: event-related potentials in a Go/Nogo task. Psychiatry Res 2003;122:169-184.

34. Prox V, Dietrich DE, Zhang Y, Emrich HM, Ohlmeier MD. Attentional processing in adults with ADHD as reflected by event-related potentials. Neurosci Lett 2007;419:236-241.

35. Wiersema R, Van Der Meere J, Antrop I, Roeyers H. State regulation in adult ADHD: an event-related potential study. J Clin Exp Neuropsychol 2006;28:1113-1126.

36. Fallgatter AJ, Ehlis AC, Seifert J, Strik WK, Scheuerpflug P, Zillessen $\mathrm{KE}$, et al. Altered response control and anterior cingulate function in attention-deficit/hyperactivity disorder boys. Clin Neurophysiol 2004; 115:973-981.

37. Woltering S, Liu Z, Rokeach A, Tannock R. Neurophysiological differences in inhibitory control between adults with $\mathrm{ADHD}$ and their peers. Neuropsychologia 2013;51:1888-1895.

38. Gow RV, Rubia K, Taylor E, Vallée-Tourangeau F, Matsudaira T, Ibrahimovic A, et al. Abnormal centroparietal ERP response in predominantly medication-naive adolescent boys with ADHD during both response inhibition and execution. J Clin Neurophysiol 2012;29:181-189.

39. Wild-Wall N, Oades RD, Schmidt-Wessels M, Christiansen H, Falkenstein M. Neural activity associated with executive functions in adolescents with attention-deficit/hyperactivity disorder (ADHD). Int J Psychophysiol 2009;74:19-27.

40. Broyd SJ, Johnstone SJ, Barry RJ, Clarke AR, McCarthy R, Selikowitz $\mathrm{M}$, et al. The effect of methylphenidate on response inhibition and the event-related potential of children with attention deficit/hyperactivity disorder. Int J Psychophysiol 2005;58:47-58.

41. Pliszka SR, Liotti M, Woldorff MG. Inhibitory control in children with attention-deficit/hyperactivity disorder: event-related potentials identify the processing component and timing of an impaired right-frontal response-inhibition mechanism. Biol Psychiatry 2000;48:238-246.

42. Smith JL, Johnstone SJ, Barry RJ. Inhibitory processing during the Go/ NoGo task: an ERP analysis of children with attention-deficit/hyperactivity disorder. Clin Neurophysiol 2004;115:1320-1331.

43. Jon DI, Hong N, Yoon BH, Jung HY, Ha K, Shin YC, et al. Validity and reliability of the Korean version of the Mood Disorder Questionnaire. Compr Psychiatry 2009;50:286-291.

44. Lim SY, Lee EJ, Jeong SW, Kim HC, Jeong CH, Jeon TY, et al. The validation study of Beck Depression Scale 2 in Korean version. Anxiety Mood 2011;7:48-53.

45. Kim J, Shin D. A standardization study of state-trait anxiety inventory in Korea. New Med J 1978;21:1223-1229.

46. Adler LA, Spencer T, Faraone SV, Kessler RC, Howes MJ, Biederman J, et al. Validity of pilot Adult ADHD Self-Report Scale (ASRS) to rate adult ADHD symptoms. Ann Clin Psychiatry 2006;18:145-148.

47. Kim S, Kim MS. Deficits in verbal working memory among college students with attention-deficit/hyperactivity disorder traits: an eventrelated potential study. Clin Psychopharmacol Neurosci 2016;14:64-73.

48. Kim JS, Kim S, Jung W, Im CH, Lee SH. Auditory evoked potential could reflect emotional sensitivity and impulsivity. Sci Rep 2016;6:37683.

49. Haukoos JS, Lewis RJ. Advanced statistics: bootstrapping confidence intervals for statistics with "difficult" distributions. Acad Emerg Med 2005; 12:360-365.

50. Ruscio J. Constructing confidence intervals for Spearman's rank correlation with ordinal data: a simulation study comparing analytic and bootstrap methods. J Mod Appl Stat Methods 2008;7:416-434.

51. Pernet CR, Wilcox RR, Rousselet GA. Robust correlation analyses: false positive and power validation using a new open source matlab toolbox. Front Psychol 2013;3:606.

52. Brodeur DA, Pond M. The development of selective attention in children with attention deficit hyperactivity disorder. J Abnorm Child Psychol 2001;29:229-239.

53. Rubia K, Smith A, Taylor E. Performance of children with attention deficit hyperactivity disorder (ADHD) on a test battery of impulsiveness. Child Neuropsychol 2007;13:276-304.

54. Heinrich H, Moll G, Dickhaus H, Kolev V, Yordanova J, Rothenberger A. Time-on-task analysis using wavelet networks in an event-related potential study on attention-deficit hyperactivity disorder. Clin Neurophysiol 2001;112:1280-1287.

55. Missonnier P, Hasler R, Perroud N, Herrmann FR, Millet P, Richiardi J, et al. EEG anomalies in adult ADHD subjects performing a working 
memory task. Neuroscience 2013;241:135-146.

56. Anjana Y, Khaliq F, Vaney N. Event-related potentials study in attention deficit hyperactivity disorder. Funct Neurol 2010;25:87-92.

57. Sunohara GA, Malone MA, Rovet J, Humphries T, Roberts W, Taylor MJ. Effect of methylphenidate on attention in children with attention deficit hyperactivity disorder (ADHD): ERP evidence. Neuropsychopharmacology 1999;21:218-228.

58. Ritter W, Ford JM, Gaillard AW, Harter MR, Kutas M, Näätänen R, et al. Cognition and event-related potentials: I. The relation of negative potentials and cognitive processes. Ann N Y Acad Sci 1984;425:24-38.

59. Snyder E, Hillyard SA. Long-latency evoked potentials to irrelevant, deviant stimuli. Behav Biol 1976;16:319-331.

60. Donkers FC, Van Boxtel GJ. The N2 in go/no-go tasks reflects conflict monitoring not response inhibition. Brain Cogn 2004;56:165-176.

61. Rucklidge JJ. Gender differences in attention-deficit/hyperactivity disorder. Psychiatr Clin North Am 2010;33:357-373. 